Asian J. Med. Biol. Res. 2020, 6 (2), 229-236; doi: 10.3329/ajmbr.v6i2.48054

\author{
Asian Journal of \\ Medical and Biological Research \\ ISSN 2411-4472 (Print) 2412-5571 (Online) \\ www.ebupress.com/journal/ajmbr
}

\title{
Article \\ Recombinant leptospiral immunoglobulin like B protein based latex agglutination test for serodiagnosis of human leptospirosis
}

\author{
Yosef Deneke ${ }^{1 *}$, Rajib Deb ${ }^{2}$ and S. M. Lutful Kabir ${ }^{3}$ \\ ${ }^{1}$ School of Veterinary Medicine, Jimma University College of Agriculture and Veterinary Medicine, Jimma, \\ Ethiopia \\ ${ }^{2}$ Scientist (SS) \& Officer, I/C ITMU ICAR-Central Institute for Research on Cattle, Indian Council of \\ Agricultural Research, Grass Farm Road, Meerut-250 001,Uttar Pradesh, India \\ ${ }^{3}$ Department of Microbiology and Hygiene, Bangladesh Agricultural University, Mymensingh-2202, \\ Bangladesh
}

*Corresponding Author: Yosef Deneke, Jimma Univesity College of Agriculture and Veterinary Medicine, P.O. Box 307, Jimma, Ethiopia. E-mail: yosefdeneke@yahoo.com

Received: 06 May 2020/Accepted: 25 June 2020/ Published: 30 June 2020

\begin{abstract}
Humans get leptospirosis by contact with fresh water, damp soil, or vegetation contaminated by the urine of infected animals, swallowing contaminated food or water or while working in contaminated flood plains or at wet agricultural settings. The bacteria enter the body through abrasions in the skin and mucous membranes. In the present study recombinant LigB protein is employed in latex agglutination test, which is a cross reacting lipoprotein able to detect acute infection caused by any pathogenic leptospiral serovars. It was employed for serodiagnosis of leptospirosis. The $46 \mathrm{KDa} 6 \mathrm{X}$ His tagged LigB protein, obtained by IPTG induction of recombinant $E$. coli M15 cells containing the N-terminal region of LigB gee in ${ }_{\mathrm{P}} \mathrm{QE} 30$ expression vector, was purified by Ni-NTA affinity chromatography and adsorbed on latex bead surface for performing latex agglutination test against leptospirosis suspected human sera. A total of 28 human sera samples were received from Post Graduate Institute of Medical Education \& Research (PGIMER), Chandigarh India, which tested positive by IgM ELISA test kit were subjected to both rLigB based LAT and MAT. All the 28 sera showed seropositivity by both the tests. Icterohaemorrahigae was the predominant serovar followed by Javanica and Grippotyphosa. Six out seven sera samples received from Indian Veterinary research Institute, Human Hospital and City Hospital, Bareilly were tested positive both by rLAT and MAT. The result showed that sera were tested positive by rLigB based LAT, which were reconfirmed using microscopic agglutination test (MAT). The results from LAT were in concordance with MAT. In conclusion, rLigB based LAT is a rapid, reliable diagnostic tool at resource poor and remote diagnostic centers with high sensitivity and specificity, under laboratory and field conditions, for the detection of leptospirosis.
\end{abstract}

Keywords: human; leptospirosis; LigB; MAT; rLig B based LAT

\section{Introduction}

Leptospirosis is considered as an important reemerging, zoonotic disease caused by pathogenic spirochetes of the genus Leptospira (Faine, 1982). Although traditionally considered an occupational risk among persons exposed to infected animal urine or contaminated water (Faine, et al., 1999), leptospirosis is becoming an important cause of febrile illness in tropical environments worldwide (Farr, 1995). Resurgent interest in leptospirosis has resulted from large outbreaks associated with recreational exposures (CDC, 1998 and 2000), and epidemics of leptospirosis- associated severe pulmonary hemorrhage syndrome (Zaki and Shieh, 1996; Yersin et al., 2000).

The risk of infection is occurring due to contact with contaminated environments, infected wild animals as well as with synanthropic animals and rodents (Tilahun et al., 2013). Leptospirosis has been known to affect both 
man and numerous mammalian species worldwide resulting in morbidity and mortality. Infection in domestic animals and wildlife can lead to economic loss and pose a potential spread to the communities. The disease can be directly transmitted through contact with secretions, blood or urine of infected animals, or indirectly through water contaminated mainly with urine of reservoir animals (Murry, 1990; Bharti et al., 2003; Sharma, 2003). Leptospirosis has been recognized as a re-emerging global public health problem due to the increased incidence in both developing and developed countries (Levett, 2001; Vijayachari et al., 2008). Global warming that leads to extreme weather events such as cyclones and floods, increased rainfall, and increased world population and urbanization are considered as the factors associated with the upsurge in the incidence of leptospirosis, as well as the magnitude of outbreaks (Levett, 2000; Hartskeerl et al., 2011). Generally, the prevention of leptospirosis can be considered an excellent example of "One Health", where the relationship between humans, animals and ecosystems needs be considered to better understand and manage the disease. Subsequently, any research and control effort requires a truly multidisciplinary and coordinated approach (Jancloes et al., 2014).

In humans, leptospirosis is manifested as high fever, jaundice, nausea and vomiting, cephalgia, mayagia especially in lower limbs such as calf muscles, epistaxis, chest pain, dry cough which later progress to Haemoptysis, haemorrhagic pneumonia, meningal involvement which leads to mental symptoms of delirium and hallucination, conjunctival suffusion, massive hemorrhages especially in gastrointestinal tract and adrenal glands and multiple organ failure mainly the liver and kidney (Ferrat, 1990; Bhari et al., 2003; Singh et al., 1999).

The primary reservoir hosts for most Leptospira serovars are wild mammals, particularly rodents. Reservoir hosts among domestic animals includes cattle, dogs, sheep and pigs and they may act as carriers for several months (temporary carrier) (Srivastava et al., 2006), while rodents usually remain carrier throughout their life (permanent carrier). Rodents are therefore considered as the major reservoir of infection (Waktole et al., 2016).

Microscopic Agglutination Test (MAT) has been the serological test of choice for the diagnosis of Leptospirosis and is also considered to be the gold standard test for detecting leptospirosis. The test is highly sensitive, serovar, serogroup specific and performed on a paired sera collected from acute and convalescent cases. MAT shows and find out a sero-conversion or a four-fold rise in antibody titer, on sera collected during the acute and convalescent stage of the disease, which is the evidence of current or recent infection (Cole et al., 1973; Vijayachari et al., 2001). Since collection of convalescent serum sample is difficult in routine practice, several disease investigator usually consider a titer of 1 in 100 as a significant titer of diagnosis without considering the endemicity or baseline titers in the community. MAT, however, requires the use of several leptospiral serovars in their active growth phase. But the maintenance of their culture is difficult, expensive, tedious and time consuming (Theirmann, 1984; Cousins et al., 1985; Bolin et al., 1989).

Therefore, more widely acceptable approach of serodiagnosis like ELISA, LeptDipstck, Lepto-dri-dot, Leptolateral flow, Latex agglutination test have been developed, which take the advantage of using genus specific proteins present in the outer membrane of the pathogenic leptospiral organism (Guerriro et al., 2001; Sehgal et al., 1999 and 2003; Vijayachari et al., 2002).

There are three classes of leptospiral outer membrane proteins (OMPs) which have been identified and used for diagnostic purposes. The most abundant class comprises the outer membrane lipoproteins which includes immune-dominat protein antigen LipL32 (Haake et al., 2000), Lip L36, which is down regulated protein in vivo (Haake et al., 1998), LipL48 (Haake and Matsungea, 2002), LipL41 which is surfaced exposed (Shang et al., 1996) and bacterial immunoglobulin like domain proteins LigA and LigB (Palaniappan et al., 2002; Matsunga et al., 2003).

The antigens which are well characterized for its diagnostic potential so far are LipL32 and LipL41 (Branger et al., 2001). Apart from these two lipoproteins, LigA and LigB proteins are drawing much attention. Anti-LigB IgM antibodies were found in sera of $92 \%$ of patients during the acute phase leptospirosis (Croda et al., 2007). The research workers opined that the use of these markers may aid the prompt and timely diagnosis required to reduce the high mortality associated with severe form of the disease. Moreover, recent studies indicated the use of N-terminal conserved region of LigB protein is useful for discriminating between naturally infected and vaccinated animals (Palaniappan et al., 2004). Therefore the aims of the present study were 1) to standardize a diagnostic test like, latex agglutination test using recombinant LigB protein with sera samples collected from human hospitals 2) to comparatively determine the efficacy of rLigB latex agglutination test and microscopic agglutination test. 
2. Materials and Methods

\subsection{Recombinant LigB protein expression and coating on latex beads}

A set of primers has been designed in order to express the $\mathrm{N}$-terminal conserved region of LigB gene, targeting a $1200 \mathrm{bp}$ long region of the $\operatorname{LigB}$ gene. A polymerase chain reaction was performed to amplify the $1200 \mathrm{bp}$ long conserved $\mathrm{N}$-terminal region of $\operatorname{LigB}$ gene. The amplicon was extracted from gel according to manufacturer instruction. Using the PCR product as a template, a nested PCR was performed using a set of internal primers which gave rise to a product of $600 \mathrm{bp}$ by length. The $1200 \mathrm{bp}$ amplicon was then inserted in to TA cloning vector pTZ57R by using DNA ligase enzymes. This recombinant vector was used to transfer competent E. coli $\mathrm{DH} 5 \alpha$ cells treated with chilled $0.1 \mathrm{M} \mathrm{CaCl}_{2}$ solution. Then, the recombinant cloned obtained were plated on Laura Bertani ampicillin plate to select the positive clones. In order to confirm the recombinants colony PCR and restriction digestion (RE) of the vector using SacI and HindIII enzymes were done. The insert released from pTZ57R vector was ligated to pQE30 expression vector treated with the same set of RE enzymes and was transformed in to competent M15 cells of E. coli and the recombinant obtained were plated on LB ampicillin plates containing kanamycin. Then, colony PCR and RE digestion of the pQE30 vector using SacI and HindIII enzymes were also done for confirmation. The confirmed recombinant cells were used for expression of LigB gene by inducing the cells with $1 \mathrm{mM}$ Isopropyl B-D-1-thiogalactopyranoside (IPTG) during the log phase of growth and SDS-PAGE was then performed to check for the expression the recombinant protein. The leptospiral immunoglobulin like B protein appeared as a thick band at the expected size of 46KDa. Later the minimum concentration required for the induction of LigB protein was determined to be $0.1 \mathrm{mM}$ IPTG. The time kinetics for the recombinant protein in SDS PAGE staring from two hours after induction and after eight hours maximum amount of LigB protein was detected in SDS-PAGE. The production of the recombinant LigB protein in a large amount was achieved by inoculation a $0.5 \mathrm{ml}$ of bacterial culture in $100 \mathrm{ml}$ of LB broth containing ampicillin and kanamycin. The bacterial cells were harvested by centrifugation and the bacterial pellet obtained was dissolved in lysis buffer with a $\mathrm{PH}$ of 8.0 and kept in a rocking (horizontal shaker) platform for two hours. The lysis buffer containing lysed bacterial cells was then centrifuged at 10,000 rpm for 20 minutes. The clear supernatant obtained was passed tough NI-NTA agarose chromatography column. The $6 \mathrm{X}$ histidine tagged $\mathrm{N}$-terminal portion of the LigB protein helps the protein to bind to $\mathrm{Ni}$ present in the chromatography column. The wash buffer at a $\mathrm{PH}$ of 6.3 was used to wash away any unbound protein. The bound LigB protein was eluted using elusion buffer at a $\mathrm{PH}$ of 4.5. The presence of purified protein was then determined using SDS-PAGE and the fraction E3 - E6 $(0.5 \mathrm{ml}$ each) contained maximum concentration of the protein. A dialysis of these fractions against PBS was conducted to remove urea. The dialyzed protein was used to coat the latex beads were used which was used for performing latex agglutination test against human sera. These sensitized latex beads were stored at $4^{0} \mathrm{C}$ and used for performing LAT test against human sera $(\mathrm{n}=28)$ collected from Post Graduate Institute of Medical Education \& Research (PGIMER), Chandigarh and from Indian Veterinary Research Institute, Human Hospital and City Hospital, Bareilly, India, for the detection of anti-LigB antibodies of leptospirosis.

\section{Results}

\subsection{Polymerase chain reaction amplification, $r$ Lig $B$ protein expression}

The result of PCR (1200 bp amplicon) confirming the N-terminal conserved region of LigB gene and nested PCR (600 bp amplicon) for confirming the PCR product were shown in Figure 1 and 2 respectively. The clones CL1, CL2, CL3, CL5, CL6 and CL8 expressed rLigB protein upon IPTG induction (Figure 3). The minimum concentration required for the induction of LigB protein was determined to be $0.1 \mathrm{mM}$ IPTG. The time kinetics for the recombinant LigB protein expression showed that detectable amount of recombinant protein was present in SDS PAGE starting from two hours after induction and after eight hours maximum amount of LigB protein was detected in SDS PAGE. SDS PAGE of purified rLigB protein was showed in Figure 4. The elution fractions E4-E6 $(0.5 \mathrm{ml}$ each) containing the maximum concentration of the protein obtained after purification of His-tagged LigB protein by Ni-NTA affinity chromatography is shown in Figure 5. Recombinant LigB based latex agglutination test with human sera (Figure 6) confirmed that recombinant LigB protein as an immunodominant protein against which antibodies are produced in the host during the active infection and anti LigB antibodies are present in sera of infected humans in higher concentration. 
Asian J. Med. Biol. Res. 2020, 6 (2)

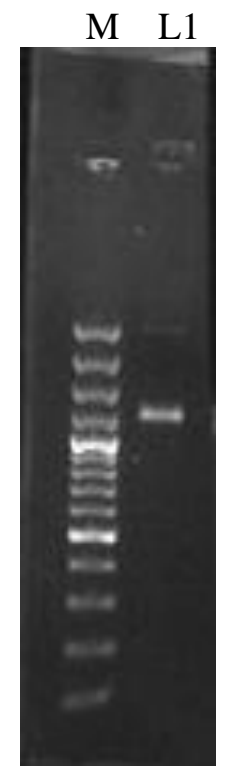

Figure 1. PCR amplification of Lig $B$ gene. M: molecular marker 100 bp; L1: Lig B gene amplicon (1200 bp)

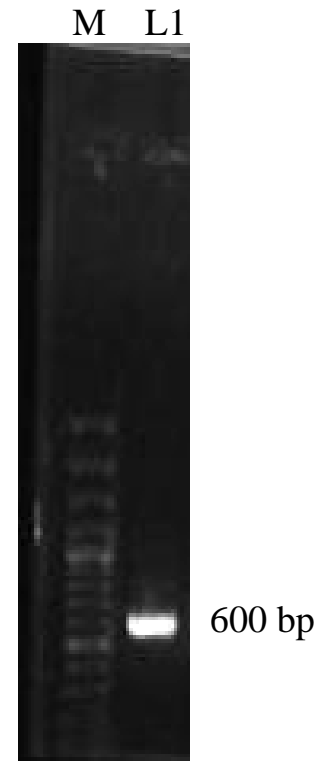

Figure 2. Nested PCR for confirmation of Lig B gene.

M: Marker; L1: Nested PCR product

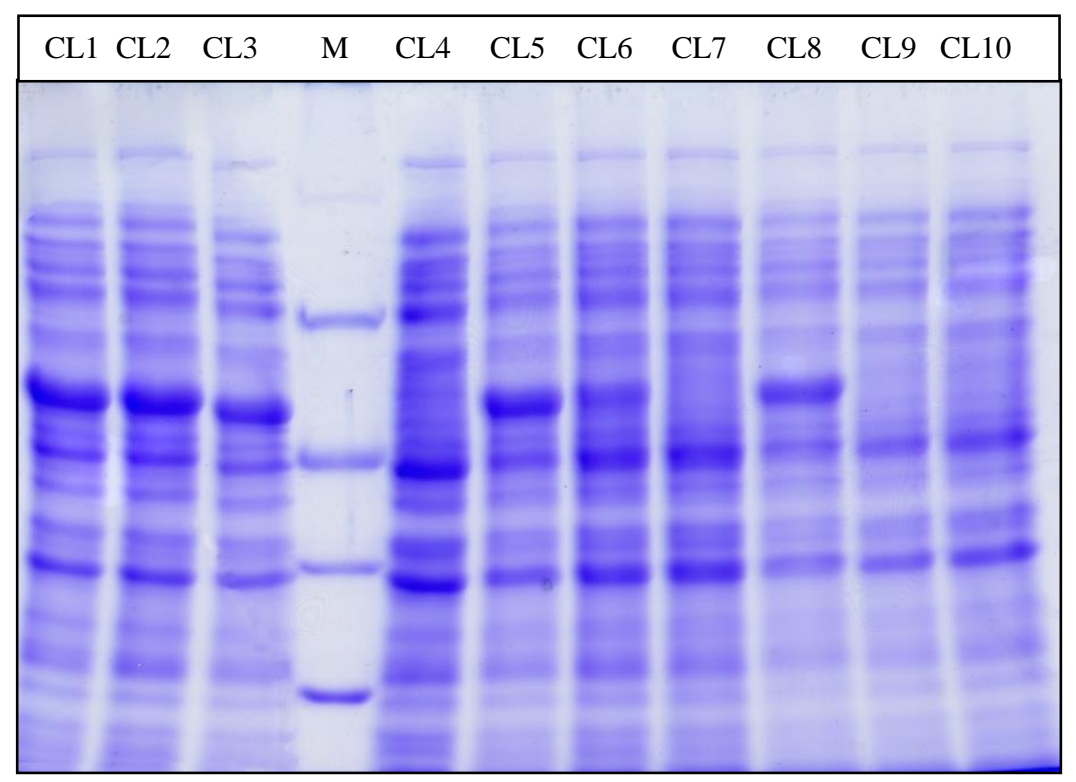

Figure 3. Clones expressing rLigB.

M: Marker; CL1-10: Clone 1-10. 


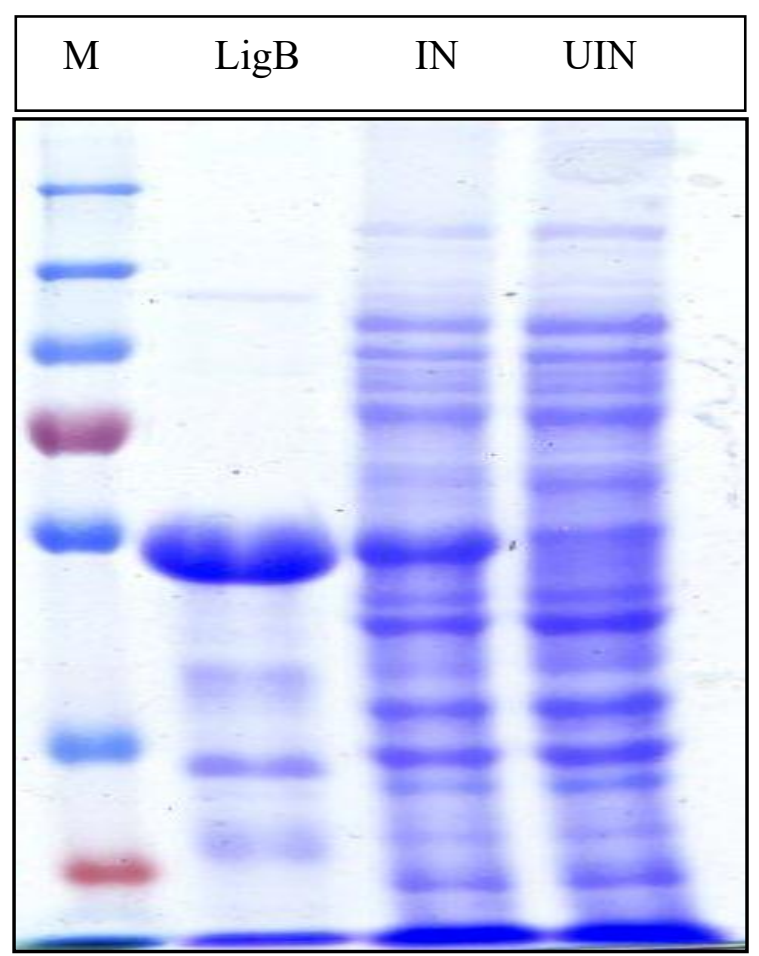

Figure 4. SDS-PAGE showing lysate of uninduced and induced M15 cells along with purified Lig B protein.

M: Marker; LigB: Lig B protein; IN: Induced M15 Cells; UIN: Uninduced M15 Cells

\begin{tabular}{llllllllll}
\hline FL & W & E1 & E2 & E3 & E4 & E5 & E6 & E7 & E8
\end{tabular}

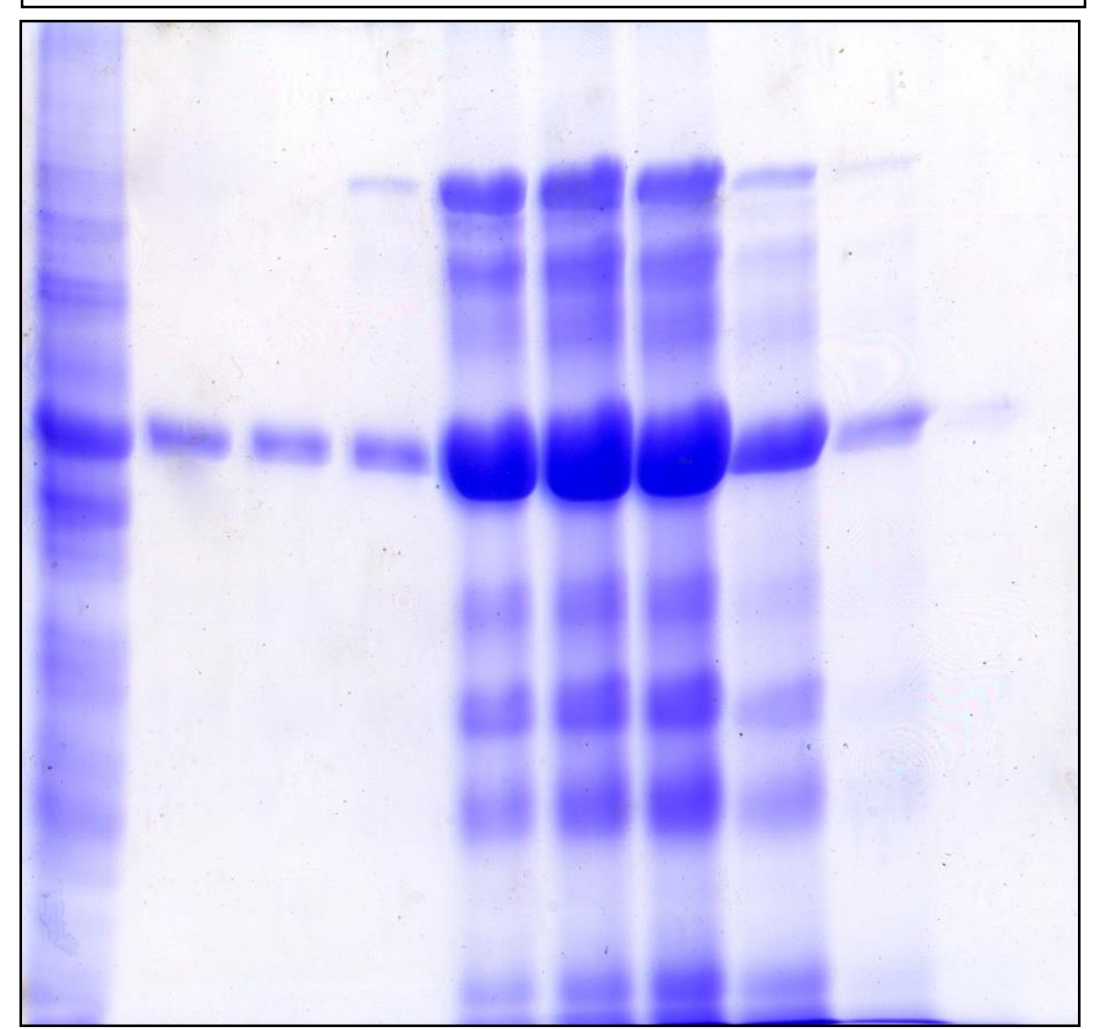

Figure 5. SDS-PAGE showing purified recombinant Lig B protein in various elusion fraction. F: Flow through; W: Wash; E1 - E 8: Elusion 1 - 8 


\subsection{Screening of human sera samples for leptospirosis using rLigB based LAT}

Twenty eight human sera samples received from Post Graduate Institute of Medical Education \& Research (PGIMER), Chandigarh which tested positive by IgM ELISA test kit were subjected to both rLigB based LAT and MAT. All the 28 sera showed seropositivity by both the tests. Icterohaemorrhagiae was the predominant serovar followed by Javanica and Grippotyphosa.

Seven human sera samples from IVRI Human Hospital and City Hospital, Bareilly were tested for Leptospirosis by both LAT (Figure 6) and MAT. Six out of seven sera tested positive and Icterohaemorrhagiae were present in all the six sera. The LAT results matched the results obtained by MAT.

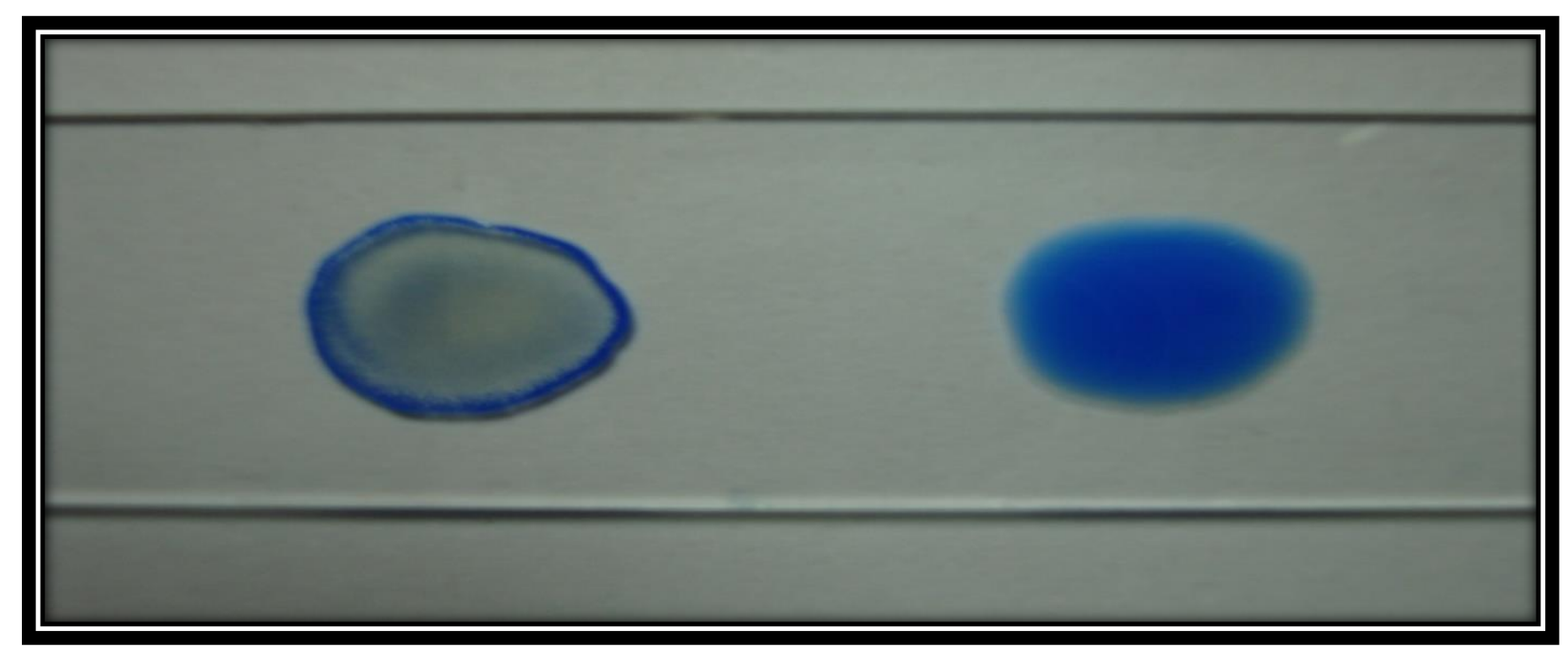

Figure 6. rLIGB based LAT of human sera samples from City Hospital, Bareilly.

\begin{tabular}{|lcl|}
\hline LAT test result: & +++ & $-v e$ \\
MAT test result: & $1: 400$ & $-v e$ \\
\hline
\end{tabular}

\section{Discussion}

As a simple, sensitive bed side diagnostic test, latex agglutination test employing recombinant LigB protein would serve for rapid and reliable diagnosis of leptospirosis under normal laboratory conditions. This diagnostic test would not require the use of highly skilled labour and the test results would be very easy to interpret. Thus LAT can be recommended in hospitals and for field studies in which speed and simplicity are crucial (Raboni et al., 2004). When the received human sera is mixed with $\mathrm{rLigB}$ coated latex beads, anti-LigB antibodies present in the sera of humans naturally infected by leptospirosis interact with the antigen leading to the formation of fine and clearly visible granular agglutination.

The intensity of the agglutination depends on concentration of the antibodies in a sera sample. Clearly visible granular agglutination indicates the presence of specific antibodies to leptospires. In stronger reactions due to sera of high antibody titre, fine granular clumps tend to settle at the edge of the circle and the reaction time to form fine granular clumps is lesser than 60 seconds. Agglutination that occurs beyond 2-3 minutes may be due to evaporation and should be treated as doubtful cases When Latex beads are sensitized with rLigB protein which are cross reactive lipoproteins found on the outer membrane of most pathogenic leptospiral serovars, this test would be able to detect infection caused by any pathogenic leptospiral serovars. Unlike MAT which employs live whole Leptospiral antigens which pose danger to the lab technician performing the test, LAT employing $\mathrm{rLigB}$ protein is completely safe and non-hazardous. The coated latex particles are stable for long periods at $4^{\circ} \mathrm{C}$ and this long shelf life and cost effectiveness of this test makes this test a very desirable diagnostic tool for detecting leptospirosis. Other potential advantages of rLigB based LAT include its portability, limited amount of generated biomedical waste. The test finds high level of application in developing countries such as India where it can be used in resource-poor settings, by investigators with only limited training (Jackson, 2006).

The present study indicated that the sensitivity and specificity of recombinant LigB protein based latex agglutination test was comparable to microscopic agglutination test which is universally considered the gold standard test for diagnosis of leptospirosis. Latex agglutination test results were generally in concordance with 
MAT and it was also observed that a quantitative relation exists between both the tests. The sera samples reacting strongly showed titer of 1:400 by MAT invariably gave +++ test result with rLigB based LAT.

\section{Conclusions}

It can be concluded that, the rLigB based latex agglutination test having sensitivity and specificity comparable to microscopic agglutination test and also possessing the additional advantage of being to serve as a pen site diagnostic test, can be easily employed, in well established hospitals as well as in mobile service clinics operating in remote, resource-poor settings.

\section{Acknowledgements}

The authors are thankful to the Director, IVRI, Izatnagar, India for providing the facilities to carry out this study.

\section{Conflict of interest}

None to declare.

\section{References}

Bharti AR, JE Nally, JN Ricaldi, MA Matthias, MM Diaz, MA Lovett, PN Levett, RH Gilman, MR Willing, E Gotuzzo and JM Vinetz, 2003. Leptospirosis: a zoonotic disease of global importance. Lancet Infect. Dis., 3: 757-771.

Bolin CA, RL Zuerner and G Trueba, 1989. Comparison of three techniques to detect Leptospira interrogans serovar hardjo type hardjobovis in bovine urine. Ame. J. Vet. Res., 50: 1001-1003.

Branger C, C Sonrier, B Chatrenet, B Klonjkowski, N Ruvoen- Clouet, A Aubert, G Andre-Fontaine and M Eloit, 2001. Identification of the hemolysis-associated protein 1 as a cross-protective immunogen of Leptospira interrogans by adenovirus mediated vaccination. Infect. Immun., 69: 6831-6838.

CDC, 1998. Outbreak of acute febrile illness among athletes participating in triathlons-Wisconsin and Illinois. Morbidity Mortality Weekly Report, 47: 585-588.

CDC, 2000. Update: outbreak of acute febrile illness among athletes participating in EcoChallenge Sabah 2000Borneo, Malaysia. Morbidity Mortality Weekly Report, 50: 21-24.

Cole J R, CR Sulzer and AR Pursell, 1973. Improved microtechnique for the leptospiral microscopic agglutination test. Appl. Microbiol., 25: 976-980.

Cousins DV, GM Robertson and L Hustas, 1985. The use of the enzyme-linked immunosorbent assay (ELISA) to detect the IgM and IgG antibody response to Leptospira interrogans serovar hardjo, pomona and tarassovi in cattle. Vet. Microbiol., 10: 439- 450.

Croda J , J Matsunaga, A Queiroz, A Hamma, RW Riley, DA Haake, MG Reis and AI Ko, 2007. Leptospira immunoglobulin-like proteins as a serodiagnostic marker for acute leptospirosis. J. Clin. Microbiol., 45: $1528-1534$.

Faine S, 1982. Guidelines for control of leptospirosis. Geneva, World Health Organization.

Faine S, B Adler, C Bolin and P Perolat, 1999. Leptospiraand Leptospirosis. Melbourne: MediSci, xxiii, 272 p.

Farr RW, 1995. Leptospirosis. Clin. Infect. Dis., 21: 1-8.

Ferrar WE, 1990. Leptospira species (leptospirosis): Principles and Practice of Infectious Diseases. In: Mandl, G.L., Douglas, R.G., Bennet, J.E. (ed), Churchill Living stone. New York, 1813 - 1827.

Guerreiro H, J Croda, B Flannery, M Mazel, J Matsunaga, M Galvao Reis, PN Levett, AI Ko and DA Haake, 2001. Leptospiral proteins recognized during the humoral immune response to leptospirosis in humans. Infect. Immun., 69: 4958-4968.

Haake DA, C Martinich, TA Summers, ES Shang, JD Pruetz, AM McCoy, KM Mazel and CA Bolin, 1998. Characterization of leptospiral outer membrane lipoprotein LipL36: downregulation associated with late-logphase growth and mammalian Infection. Infect. Immun., 66: 1579-1587.

Haake DA, G Chao, RL Zuerner, JK Barnett, D Barnett, M Mazel, J Matsunaga, PN Levett and CA Bolin, 2000. The leptospiral major outer membrane protein LipL32 is a lipoprotein expressed during mammalian infection. Infect. Immun., 68: 2276-2285.

Haake DA and J Matsunaga, 2002. Characterization of the leptospiral outer membrane and description of three novel leptospiral membrane proteins. Infect. Immun., 70: 4936- 4945.

Hartskeerl R, M Collares-Pereira and W Ellis, 2011. Emergence, control and re-emerging leptospirosis: dynamics of infection in the changing world. Clinical Microbiology and Infection, 17: 494-501. 
Jackson CH, MB Glass, MD Ari, SL Bragg, SL Branch, CU Whittington, CN Edwards and PN Levett, 2006. Evaluation of a commercial latex agglutination assay for the serological diagnosis of leptospirosis. J. Clin. Microbiol., 44: 1853-1855.

Jancloes M, E Bertherat, C Schneider, S. Belmain, C Munozanzi, R Hartskeerl, F Costa, J Denis and J Benschop, 2014. Towards a "One Health" Strategy against Leptospirosis. In: Planet@Risk, 2(3), Special Issue on One Health (Part I/II): 204-206, Davos: Global Risk Forum GRF Davos.

Levett PN, SL Branch and CN Edwards, 2000. Detection of dengue infection in patients investigated for leptospirosis in Barbados. Am. J. Trop. Med. Hyg., 62: 112-114.

Levett PN, 2001. Leptospirosis. Clin. Microbiol. Rev., 14: 296-326.

Matsunaga J, MA Barocchi, J Croda, TA Young, Y Sanchez, I Siqueira, CA Bolin, MG Reis, LW Riley, DA Haake and AI Ko, 2003. Pathogenic Leptospira species express surface-exposed proteins belonging to the bacterial immunoglobulin super family. Mol. Microbiol., 49: 929-945.

Murray RD, 1990. A field investigation of causes of abortion in dairy cattle. Vet. Rec., 127: 543-547.

Palaniappan RU, YF Chang, SS Jusuf, S Artiushin, JF Timoney, SP McDonough, SC Barr, TJ Divers, KW Simpson, PL McDonough and HO Mohammed, 2002. Cloning and molecular characterization of an immunogenic LigA protein of Leptospira interrogans. Infect. Immun., 70: 5924-5930.

Palaniappan RU, YF Chang, F Hassan, SP McDonough, M Pough, SC Barr, KW Simpson, HO Mohammed, S Shin, P McDonough, RL Zuerner and JB Qu, 2004. Expression of leptospiral immunoglobulin-like protein by Leptospira interrogans and evaluation of its diagnostic potential in a kinetic ELISA. J. Med. Microbiol., 53: 975-984.

Raboni SM, MB Nogueira, VM Hakim, VTG Torrecilha, H Lerner and LRV Tsuchiya, 2004. Comparison of Latex agglutination with enzyme immunoassay for detection of rotavirus in faecal specimens. Am. J. Clin. Pathol., 117: 392-394.

Sehgal SC, P Vijayachari, S Sharma and AP Sugunan, 1999. LeptoDipstick - a rapid and simple method for serodiagnosis of leptospirosis in acute stage. Trans. Roy. Soc. Trop. Med. Hyg., 93: 161-164.

Sehgal SC, P Vijayachari, AP Sugunan and T Umapathi, 2003. Field application of Lepto-lateral flow for rapid diagnosis of leptospirosis. J. Med. Microbiol., 52: 1- 6.

Shang ES, TA Summers and DA Haake, 1996. Molecular cloning and sequence analysis of the gene encoding LipL41, a surface-exposed lipoprotein of pathogenic Leptospira species. Infect. Immun., 64: 2322-2330.

Sharma S, P Vijayachari, AP Sugunan and SC Sehgal, 2003. Leptospiral carrier state and seroprevalence among animal population a cross sectional sample survey in Andaman \& Nicobar Islands. Epidemiol. Infect., 131: 985-989.

Singh SS, P Vijayachari, A Sinah, AP Sugunan, MA Rashid and SC Shegal, 1999. Clinico-epidemiological study of hospitalized cases severe leptospirosis. Indian J. Med. Res., 189: 94-99.

Srivastava SK, 2006. Prospects of developing leptospiral vaccines for animals. Indian J. Med. Microbiol., 24: 331-336.

Thiermann AB, 1984. Bovine leptospirosis: Bacteriologic versus serologic diagnosis of cows at slaughter. Am. J. Vet. Res., 44: 2244- 2245.

Tilahun Z, D Reta and K Simenew, 2013. Global epidemiological overview of leptospirosis. International Journal of Microbiology Research, 4: 09-15.

Vijayachari P, AP Sugunan and SC Sehgal, 2001. Role of Microscopic Agglutination Test (MAT) as a diagnostic tool during acute stage of leptospirosis in low and high endemic areas. Indian J. Med. Res., 114: 99-106.

Vijayachari P, AP Sugunan and SC Sehgal, 2002, Evaluation of Lepto dri-dot as a rapid test for the diagnosis of leptospirosis. Epidemiol. Infect., 129: 617-621.

Vijayachari P, AP Sugunan and A Shriram, 2008. Leptospirosis: an emerging global public health problem. Journal of Biosciences, 33: 557-569.

Waktole Y, G Bashahun and A Nejash, 2016. Leptospirosis in animal and its Public Health Implications, a review. World Applied Science Journal, 34: 845-853.

Yersin C, B Pascal, M Fabrice, C Jan, L Manola, Van R Marc and P Philippe, 2000. Pulmonary haemorrhage as a predominant cause of death in leptospirosis in Seychelles. Transactions of the Royal Society of Tropical Medicine and Hygiene, 94: 71-76.

Zaki SR and WJ Shieh, 1996. Leptospirosis Associated With Outbreak of Acute Febrile Illness and Pulmonary Haemorrhage, Nicaragua, 1995. The Epidemic Working Group at Ministry of Health in Nicaragua. Lancet, 347: 535-536. 